\title{
Understanding kidney disease in rural central Uganda - findings from a qualitative study
}

Janet Seeley $1,2, \mathrm{t}$, Elizabeth Kabunga1,t, Joseph Ssembatya 1 , Laurie Tomlinson, June Fabian4,5, Liam Smeeth, Moffat Nyirenda 1,3, Robert Newton 1,6, Robert Kalyesubula1,3,7,t, Dominic Bukenya $1, t$ on behalf of the ARK Consortium

t These authors contributed equally to this work

$1 \mathrm{MRC/UVRI}$ and LSHTM Uganda Research Unit, Entebbe, Uganda

2 Department of Global Health and Development, Faculty of Public Health and Policy, London School of Hygiene and Tropical Medicine, UK

3 Department of Non-Communicable Disease Epidemiology, Faculty of Epidemiology and Global Health, London School of Hygiene \& Tropical Medicine, UK

4 Wits Donald Gordon Medical Centre, Parktown, Johannesburg, South Africa

5 Medical Research Council/Wits University Rural Public Health and Health Transitions Research Unit (Agincourt), School of Public Health, Faculty of Health Sciences, University of the Witwatersrand, Johannesburg, South Africa.

6. Department of Health Science, University of York, UK

7 Makerere University College of Health Sciences, Kampala, Uganda

Corresponding author: Prof Janet Seeley, Department of Global Health, London School of Hygiene \& Tropical Medicine, 15-17 Tavistock Place, WC1H 9SH, UK, janet.seeley@lshtm.ac.uk, tel. +44(0)207958 8268.

\section{Running header: Understanding kidney disease in rural Uganda}

\section{Acknowledgements}

We are grateful to all the participants for giving us their time and information for this study. We thank Ronald Makanga for help with sample selection and the study clinic team for their support. We are very grateful for the contribution of Grace Tumwekwase who died at the end of 2019. Grace was an interviewer in the first phase of data collection and made a large contribution to the conduct of the study.

\section{Funding Statement}

This study was funded by the GlaxoSmithKline Africa NCD Open Lab Programme (grant ref 8111). LAT was funded by a Wellcome Trust intermediate clinical fellowship (101143/Z/13/Z). DB, RN and JS are partly funded by the UK Medical Research Council (MRC) and the UK Department for International Development (DFID) under the MRC/DFID Concordat agreement and is also part of the EDCTP2 programme supported by the European Union. JS acknowledges the support of THRiVE-2, a 
DELTAS Africa grant \# DEL-15-011 from Wellcome Trust grant \# 107742/Z/15/Z and the UK government.

The funders had no role in study design, data collection and analysis, decision to publish or preparation of the manuscript.

Conflict of interest

None of the authors has any conflict of interest to declare.

ORCID

Janet Seeley

Laurie Tomlinson

June Fabian

Liam Smeeth

Moffat Nyirenda

Robert Newton

Robert Kalyesubula

Dominic Bukenya
0000-0002-0583-5272

0000-0001-8848-9493

0000-0001-7130-9142

0000-0002-9168-6022

0000-0003-2120-4806

0000-0001-6715-9153

0000-0003-3211-163X

0000-0002-6245-8565 


\section{Abstract}

As part of a multicentre study on kidney disease (ARK) undertaken in Malawi, South Africa and Uganda we undertook a social science component in Uganda to gather information on people's understandings and perceptions of a diagnosis of kidney dysfunction, treatment and treatment seeking. We recruited 46 people who had been given information about kidney dysfunction and had been found to have some, usually early, signs of mild impairment. Data were collected during two in-depth interviews. Most participants had heard of the condition, but half denied knowledge of the health status of their kidneys or receiving results of tests from the clinic team. This response may have been linked to a lack of symptoms, for those with early stage kidney dysfunction. The treatment people reported receiving caused some uncertainty about condition severity. This may be because several people were treated for other conditions (such as urinary tract infections) and did not require treatment specifically for kidney disease. In our study, participants assessed illness severity based on symptoms and treatment and compared with the progression of other conditions.

Key words: Kidney dysfunction; kidney impairment; Non-communicable diseases; Qualitative methods; Uganda 


\section{Introduction}

Chronic kidney disease is a long-term condition with few symptoms until it is very advanced, and the symptoms are non-specific. The causes of kidney disease in subSaharan Africa are poorly understood, but it appears to be a consequence of a number of factors, including some genetic traits endemic to the region such as sickle cell disease, and other glomerulonephritides, and emerging non-communicable conditions (diabetes, hypertension and obesity) (Ene-lordache et al., 2016; Jha et al., 2013; Kalyesubula et al., 2017). Infectious diseases, including HIV-associated kidney disease and other factors such as herbal remedies are also thought to be important in susceptibility to kidney disease (Jha, et al., 2013; Naicker, Rahmanian, \& Kopp, 2015; Perico and Remuzzi, 2014).

Public knowledge levels on the normal functioning of the kidney in places such as the United Kingdom and the United States are limited (Gaffney et al., 2014; Kazley, Johnson, Simpson, Chavin, \& Baliga, 2014; Slevin and Taylor, 2015). In a metaanalysis and systematic review of patient experience of a chronic kidney disease diagnosis Teasdale and colleagues (2017) documented limited understanding of kidney disease, with a wide-range of beliefs on the causes of disease and concerns about progression among patients participating in qualitative research studies in the United States, Australia, Brazil, Canada, the Netherlands, Taiwan and Sweden. A large crosssectional survey in 12 countries spread across six regions also showed limited awareness of chronic kidney disease among people who were at risk of the disease (Ene-lordache, et al., 2016). Kazley and colleagues (2014) asked health care providers in the United States about the knowledge and response to diagnosis of their African 
American patients in South Carolina. Those providers reported that most of their patients denied having the condition and were reluctant to undergo treatment.

A systematic review, published in 2014 , showed that the overall prevalence of chronic kidney disease in sub-Saharan Africa (sSA) was 13.9\% (95\% Cl 12.2-15.7) (Stanifer et al., 2014). However, the true prevalence is unknown as these studies were drawn from convenience samples, often in hospitals or populations at high-risk for kidney disease, as well as uncertainty about how to estimate kidney function in SSA (Kalyesubula et al., 2018). The search for an accurate measure has over the last two decades resulted in several equations being developed to estimate Glomerular Filtration Rate (GFR) based on levels of serum creatinine, an endogenous breakdown product of creatine phosphate produced by muscle which provides information on kidney function. However, the equations to estimate GFR were developed among populations with a low proportion of ethnic Africans and these equations have had limited validation among people in SSA (Kalyesubula, et al., 2018). The accuracy of these equations is likely to be poor since serum creatinine levels vary substantially with race, diet and nutritional status (Delanaye, Mariat, Maillard, Krzesinski, \& Cavalier, 2011).

To address the gaps in knowledge regarding risk for kidney disease, kidney disease prevalence and optimal measurement of kidney function in SSA, a multicentre study, the African Research on Kidney Disease (ARK) Study (Kalyesubula et al., 2020)_was recently undertaken in Malawi, South Africa and Uganda. All participating sites are Health and Demographic Surveillance sites, enabling a cross-sectional populationbased determination of the prevalence of kidney dysfunction in adults from 20 to 80 years of age, followed by direct measurement of GFR using the excretion of intravenous 
iohexol to examine the accuracy of different estimating equations for GFR (eGFR) (Fabian, Kalyesubula, Tomlinson, Crampin, \& Naicker, 2019). Previous studies using iohexol to measure GFR in SSA had been relatively small and included few people with impaired kidney function (Bukabau et al., 2018; Sagou Yayo et al., 2016; Wyatt et al., 2013).

In Uganda this survey was embedded within the General Population Cohort in a rural sub-county in Kalungu District, central Uganda, about 150 kilometres south of Kampala. The cohort was established 30 years ago, initially for the study of the epidemiology of HIV and AIDS, but in recent years the research focus has broadened to include other chronic communicable and non-communicable conditions. From 1990 the cohort participants were followed up annually, however since 2011 follow-up has been biennial (Asiki et al., 2013).

A social science component of the ARK Study was embedded within the Ugandan site with the aim of gathering information on people's understanding of information on kidney disease and perceptions of a diagnosis of kidney disease, treatment and treatment seeking. In this paper we report the findings from this social science component.

Most of the participants who were told that they were in the early stages of impaired kidney function in our study population had an asymptomatic condition, which did not at that time require specific treatment. We therefore focus in this paper on people's understanding of kidney disease and their response to the information they were given on disease, as well as treatment and management of kidney disease. 
We draw on the work of Leventhal and colleagues (Leventhal, Phillips, \& Burns, 2016) and concepts from the 'Common-Sense Model of Self-Regulation' in our discussion of how the response to information on an asymptomatic chronic condition (at an early stage of potential disease) may be shaped by the experience of people's knowledge of acute conditions, including an understanding of symptoms and expectations of a short time-line for the illness development. In this regard, the early stages of kidney disease may mirror the early experience of HIV-infection, with which one may live for months or

years without experiencing ill-health, or when sickness occurs it is not necessarily linked to symptoms that identify a specific condition (Willard et al., 2009). So, a person may not realise that they have the condition unless tested and diagnosed by a health-worker, which may not happen at a primary health centre if symptoms are non-specific. The reference here to HIV is also relevant because this study took place in an area that was at one stage the epi-centre of the HIV epidemic; this may in itself influence expectations about disease progression and treatment approaches.

\section{Methods}

As noted above, the study area is in rural central Uganda. The local livelihoods are based mainly around agriculture with families growing crops such as coffee, tobacco, bananas, beans, maize, potatoes and cassava. Migration by some family members (younger women and men) to urban areas and fishing sites for wage work is common. Income is also made from making bricks, growing eucalyptus (and some pine) for sale and jobs in shops and bars in trading centres. The main ethnic group in the study area is the Baganda with some immigrants originating from Rwanda and Tanzania. Most of 
the population are Roman Catholics and the rest are Protestants and Muslims. Luganda is the main language spoken.

The study focused on people who as part of the ARK study had been given information about kidney dysfunction and had been found to have some, usually early, signs of impairment (most people in the sample were asymptomatic), exploring their reaction to being given this information, and their understanding of kidney dysfunction and (possible future) treatment. We recruited a random sample of 46 people from among those who were found to have estimated GFR $<90 \mathrm{mls} / \mathrm{min} / 1.73 \mathrm{~m} 2$ during the recruitment of the 1000 participants for the iohexol component of the ARK Study (Kalyesubula, et al., 2018). We did not confirm that kidney function remained at this level or below after three months which would be required to formally diagnose Chronic Kidney Disease (Kalyesubula, et al., 2018). Data were collected during two in-depth interviews with each participant. The first interview was used to ask about day to day life, recent life history events and begin to talk about health seeking behaviour. The second interview built on this information and probed more extensively for information around health seeking, use of traditional treatments and awareness of kidney impairment prior to the screening for this study.

Most interviews were conducted at the participants' homes. Some participants chose to be interviewed at the clinic. The interviews were conducted by two Ugandan interviewers (a man and a woman) with experience in qualitative data collection methods. The interviews were conducted in the local language (Luganda) and lasted up to one hour. Besides audio-recording the interviews, interviewers took field notes. The interviewers transcribed the interviews and translated them into English. The transcripts 
were reviewed throughout the course of the study by a senior social scientist, to ensure quality and provide continuous feedback on interview content and format.

\section{Data analysis}

Data from 46 participants were included in the final analysis for this paper. A manual thematic content analysis approach, guided by the research questions listed above and constructs emerging from the data, was used to distil key concepts from the interviews. At the first level of analysis, the interviews were read repeatedly by the interviewers (EK and JSs) and a senior social scientist (DB), and then coded by EK and JSs, in consultation with DB and JS. Following the coding, EK and JSs prepared detailed analytical memos on reactions to information on kidney disease; being given information on their own kidney dysfunction; offers of treatment and their own treatment seeking. From these narratives JS, DB, EK and JSs distilled the findings for this paper.

\section{Ethical Considerations}

Ethics approvals were obtained from the Uganda Virus Research Institute, Research Ethics Committee (UVRI-REC) and the Uganda National Council for Science and Technology (UNCST).

If medical conditions were diagnosed through study screening, the participants were referred to appropriate medical facilities including the local study clinic which had enhanced resources as a result of the ongoing research work. With regards to this study, where most participants were found to have only mild impairment of kidney function, those in need of follow-up were referred to the local clinic, while participants 
found to have advanced impairment were referred to appropriate nephrology services as directed by the study physicians (Kalyesubula, et al., 2020).

\section{Results}

The majority of participants in the social science study sample were classified as having Stage 2 kidney dysfunction according to the staging given by Kidney Disease Improving Global Outcomes (KDIGO) CKD Work Group (Kidney Disease Improving Global Outcomes (KDIGO) CKD Work Group, 2013). People with Stage 2 kidney dysfunction do not usually require treatment unless there are complications because of another condition. Any treatment provided depends on risk factors (linked to diabetes or hypertension) and whether specific investigations are needed for kidney disease. Table 1 provides an overview of the kidney disease staging, age and sex of participants in this study. 
Table 1 - Kidney disease staging, age range and sex of participants

\begin{tabular}{|c|c|c|c|c|c|c|c|c|c|c|c|c|c|}
\hline Chronic & $30-39$ & & $40-4$ & & $50-59$ & & $60-6$ & & $70-79$ & & 80 ye & and over & Total \\
\hline $\begin{array}{l}\text { Kidney } \\
\text { Disease } \\
\text { stage* }^{*}\end{array}$ & Male & Female & Male & Female & Male & Female & Male & Female & Male & Female & Male & female & \\
\hline 2 & 2 & 2 & & 8 & 2 & 10 & 2 & 6 & 2 & 3 & 3 & 1 & 41 \\
\hline $3 a$ & & & & & & 1 & & & 1 & & & & 2 \\
\hline $3 b$ & & & & & & & 1 & & & & & & 1 \\
\hline 4 & & & & & 1 & & & & & & & & 1 \\
\hline 5 & & & 1 & & & & & & & & & & 1 \\
\hline Total & 2 & 2 & 1 & 8 & 3 & 11 & 3 & 6 & 3 & 3 & 3 & 1 & 46 \\
\hline
\end{tabular}

* The staging level of kidney dysfunction was based on one measure of eGFR. The five stages of CKD, GFR and treatment for each stage are:

- (Stage 1 - with normal or high GFR (GFR $\left.>90 \mathrm{ml} / \mathrm{min} / 1.73 \mathrm{~m}_{2}\right)$. No treatment necessary)

- Stage 2 - mild CKD (GFR = 60-89 ml/min/1.73m2). Advice on healthy lifestyle: maintaining a healthy weight, smoking cessation, exercise levels. Monitoring and treating blood pressure, diabetes and other comorbidities.

- Stage 3A - moderate CKD (GFR = 45-59 $\left.\mathrm{ml} / \mathrm{min} / 1.73 \mathrm{~m}_{2}\right)$. As Stage 2

- Stage 3B - moderate CKD (GFR = 30-44 $\left.\mathrm{ml} / \mathrm{min} / 1.73 \mathrm{~m}_{2}\right)$. As Stage 2

- Stage 4 - Severe CKD (GFR = 15-29 ml/min/1.73m2). As Stage 2. Management of fluid balance, blood pressure, anaemia, bone health and dietary changes may be required. .

- Stage 5 - End stage CKD (GFR $=<15 \mathrm{ml} / \mathrm{min} / 1.73 \mathrm{~m}_{2}$ ). Management of fluid balance, blood pressure, anaemia, bone health and dietary changes commonly needed. Dialysis or kidney transplant may be required to continue living. 
We present the results in three parts: the reactions participants had to information on kidney dysfunction, their reactions to information on kidney disease and then their views on any treatment they may have been offered. Many of those who participated in the study agreed to take part, not because they had symptoms, but because they saw the survey as an opportunity to have their health assessed for free by health workers from an organisation which they had known for many years. This is summed up by one 4049 year old man who said:

I have grown up seeing the organization treating people who were down because of HIV and enabling them become healthy once again although not being healed completely. Now hearing that those kidney disease researchers were health workers coming from the same organization, I could not hesitate to take part.'

\section{Reactions to being given information on kidney dysfunction}

Nearly all the people who were told that they have some signs of kidney dysfunction said that they had heard about the condition before the study began. This level of knowledge was unexpected but could be explained by people having been told about the condition when seeking care for other conditions or knowing of relatives who had been given information on the condition or conditions, which sounded similar. One woman, for example, who was living with HIV, said that she had been diagnosed with kidney problems in the past and had learnt of the condition through that experience. However, knowing the name of the condition did not, for most people, mean that they had a detailed knowledge of the condition: 
I never knew that being diabetic or hypertensive could also lead to having the kidney disease, [...] I am not aware and that persuaded me to take part.' 60-69 year old man - Stage 2.

The information provided on kidney disease during study mobilisation within the GPC led a few people to join the study because of health concerns that they had:

'It (kidney disease) is linked to severe back ache and due to what I heard about the sickness and I was also disturbed by the back pain I decided to test and find out if I have a kidney problem.' $80+$ year old man, - Stage 2.

'What mostly made me accept to participate is the swelling of the legs I experience at times which make me suspect that I could be a kidney patient too. I was even forced to ask the health worker about it but he (the health worker) comforted me not to worry and that I would get to know if the swelling was connected to that after the results come back.' 40-49 year old woman. - Stage 2.

The information provided to the participants made it clear that if someone had chronic kidney disease it was a serious condition. About half of the participants said that when kidney dysfunction was first described to them, and participation in the study offered, they were very concerned that if they were found to have it, they would not be able to finance their own treatment. Some said that they joined the study to access free treatment for that reason.

'I looked at my health and economic status; I am not all that well. I am disturbed by sickness yet I am poor. What if I have the kidney disease and I refuse to participate? Then later I get to know I am affected. Where do I begin from since 
even the money for just the daily commodities is hard for me to obtain! I decided to take part because of that!' 50-59 year old woman - Stage 2 .

The information on the seriousness of chronic kidney disease, shared by the study team, was in some cases conflated with information that people had received from other sources, which raised the concern of some participants who perceived the condition as an acute health threat:

'I had feared very much to be among those whose kidneys are affected because one of my relatives had already told me that once the kidney or the liver become infected, chances are very limited for one to survive. I know death comes to everyone but I fear dying from such a serious illness!' 70-79 year old woman Stage 2.

Participants worried not only about themselves receiving a diagnosis of kidney impairment, but that their relatives and friends may have similar health problems. Concerns about the prevalence of the condition, as well as the fears over the condition being incurable, mirror continued anxiety about HIV in this population (Bukenya et al., 2017).

\section{Reactions to being told of evidence that a person had kidney dysfunction}

All 46 participants told that they have some level of impaired kidney function, were given this information by study clinic staff and the condition explained to them. However, when talking to the social science interviewers, more than half of the participants (26/46) said that they did not have kidney dysfunction. Of these, 14 people said that they had not received their results and a further 10 said that the results they received 
had not indicated that they had such a condition. Two participants said that they had not taken part in the kidney disease screening exercise at all. Both men and women expressed these views:

'They brought some information on a piece of paper. Unfortunately, I was away for my work then they handed the paper to mzee (meaning his father) [...] I currently do not know where he placed that piece of paper.' 40-49 year old man - Stage 5. Interestingly this man also commented that his father had told him his kidneys 'were fine'.

'The health workers are the ones who know what they found. They are the ones who know what they are doing but have not disclosed to me what they found. Whether I am sick (with kidney problems) or not, I do not know.' 70-79 year old woman - Stage 2.

The health worker team confirmed that all the people sampled for the social science component had received information on the stage of kidney disease they had been identified with and results were only given to the participant, not to family members, which suggests the denial of receiving and knowing about this information was linked to worry about the condition.

A fear of the condition was expressed by others who acknowledged being told that they had kidney dysfunction, but they said that the diagnosis was unexpected. Some of these participants recalled that they had been told that the condition was not curable, 
and they worried about the high cost of treatment and how family members would manage if they became very ill.

'After getting the results, I am just there, I am completely losing strength. I am

worried. You know each time you learn you have an illness you never

anticipated; you become worried, your peace is as if taken away'. 60-69 year old man - Stage 3b.

Some wished they could have had their condition verified in a different health facility. A 50-59 year old woman mentioned others who sought such support:

Y did not have money for I would have gone to meet health workers elsewhere and find out what they would tell me about the same [kidney] issue because even my co- wife down there, who was invited in the same group, her well off children took her to Kampala for further investigation.' - Stage 3a

Six people said that they had been diagnosed with kidney dysfunction but they were doubtful that the diagnosis was correct. The reasons they doubted the diagnosis was because the test had been 'very simple', so they did not understand how such a test could diagnose a kidney disease. But also, they did not have any symptoms like pain around the lower abdomen where the kidneys are located. This suggests that the way the condition was diagnosed led to people questioning what had actually been tested. They also said that the health workers had provided limited advice on what to do to manage progression, which they would have expected if the disease was severe. 'If I was sick with the kidneys, why did the health workers at your place [study clinic] not prevent me from taking salt? They have not even told me about other 
things I should avoid if they found out that my kidney was sick. If they have not done so, have they not just put me in a worrying situation?' 70-79 year old woman. Stage 3a.

However, 10 people did react positively to news of their condition. Of these, eight reported that they accepted the information and had linked to care at a local health facility where their condition could be monitored and treatment provided if required, as advised by the health workers. If more specialist care was needed, health facility staff could refer patients to specialists at district and regional hospitals. In addition to linking to formal health care, five of the ten people said that they had disclosed their reduced kidney function diagnosis to their spouses, adult children or siblings. The two people, both older men (in their 60 s and 80 s respectively), who had not linked to care said that they were contemplating the possibility of doing so 'one day'.

\section{Reactions to advice on treatment.}

Given that half of the participants who had been found with kidney dysfunction had denied their diagnosis, it is not surprising that they also said that they were not accessing treatment. However, it is also very likely that they were participants who had only mild to moderate kidney impairment, and no treatment had been recommended for them. The lack of treatment may have led to doubts about their diagnosis, and hence a view that they were not affected. In addition, some participants were offered treatment for other conditions (urinary tract infections for example), rather than directly for kidney dysfunction, although they considered it to be treatment for kidney disease. 
The differences in treatment offered, referred to above, was confusing for some people. A few participants (four people) expressed their doubts about whether the treatment given in the study clinic was effective because of the short duration of treatment relative to the severity of the condition:

'They were just minor tablets which I took for only a week. I then kept wondering, how someone they have said has kidney disease can be given such minor treatment, yet they say the kidney disease is very bad, I was not satisfied!' She continued; 'just such tablets to treat a serious disease!' 70-79 year old woman. Stage 2.

Given that this woman did not require any treatment for kidney dysfunction it is likely that this woman had received treatment for a urinary tract infection; if she had kidney disease she would have had follow-up visits to the clinic and if the condition was severe, referral to another facility.

The short duration treatment for other conditions resulted in some people being very positive about 'kidney disease treatment'. Five people were happy about the limited treatment they received and said that they had adhered to the treatment.

'They told me 'your illness is about the kidney! Your kidneys have lots of fluids!' They started giving me drugs [...] The drugs I got from [the study clinic] were for two weeks and I took them.' 60-69 year old man. - Stage 3b.

Nine of those who did disclose their condition to the social science interviewers said that they were seeking alternative forms of treatment in combination with the medication they received from the study clinic. The decision to use alternative medicine, herbs for 
example, was mostly due to the influence of friends and relatives. The same man who had received the treatment for two weeks, went on to say:

I was taking tablets from the study clinic but then a friend directed/advised me to take some of that older woman's herbs because she is well known for treating many illnesses. What I did was to take the tablets first then after two hours I would take the herbal medicine so that it does not interfere with the tablets.' - Stage 3b.

A 60-69 year old woman, who was assessed as 'Stage 2' so would not have required specific treatment for kidney dysfunction explained her use of herbs for a condition treated at the clinic:

'Since I completed the dosage [unspecified] I obtained from the study clinic, I have been taking powder made from rosemary adding it to hot water. I learnt from that young person (indicating someone nearby) that the herb has a lot of benefits which include brain boosting'.

To sum up, we found that among people told that they had impaired kidney function, the majority had heard of the condition, but half denied knowledge of the health status of their kidneys or, in some cases, receiving any results of tests from the clinic team. The denial of the condition and delay or refusal to link to care may have been linked to a lack of symptoms for those with early stage kidney dysfunction, which may have led them to assume the information on kidney dysfunction to be incorrect. The range of treatments given to people who did report both being given information and treatment, caused some uncertainty about whether the condition was indeed serious. This was 
probably because several people were treated for other conditions (such as urinary tract infections) and did not require treatment specifically for kidney disease.

\section{Discussion}

Our findings suggest that there was limited understanding of kidney dysfunction among those told about the condition, a result which mirrors the findings of studies from elsewhere (Ene-lordache, et al., 2016; Kazley, et al., 2014; Slevin and Taylor, 2015; Teasdale, et al., 2017; Wright Nunes, Roney, Kerr, Ojo, \& Fagerlin, 2016). The lack of symptoms experienced by many of those who were told that they had impaired kidneys led them to doubt that they had the condition, a finding also corroborated elsewhere (Kazley, et al., 2014). Receiving a diagnosis provides a label for a condition, affording 'permission' to be ill (Jutel, 2009) and the packaging of symptoms with a label for treatment (Rosenberg, 2002). But when the condition is asymptomatic, a diagnosis may not provide confirmation of a condition, instead it can promote anxiety and disbelief (Walker and Rogers, 2017; Wright Nunes, et al., 2016). A desire on the part of a medical practitioners not to alarm a patient or overburden someone with other noncommunicable conditions with a diagnosis of asymptomatic kidney disease may result in non or partial disclosure (Crinson, Gallagher, Thomas, \& de Lusignan, 2010; DakerWhite et al., 2015; Nash, Garg, Brimble, \& Markle-Reid, 2018). It is also important to note that there is some uncertainty over the interpretation of kidney dysfunction in older people (Hart and Anderson, 2018; Nguyen and Goldfarb, 2012). Many of our respondents were over 60 years of age and mild kidney impairment may have been part of the ageing process and the staging provided during the study was not confirmed with repeat testing for those with early stage kidney dysfunction. 
Other research in the UK and Australia shows that perceptions of chronic kidney disease, informed by the information that patients have on the condition, shapes patients wellbeing and their response to treatment (Kazley, et al., 2014), as well as influencing health outcomes (Chilcot, 2012). Indeed, Nash and colleagues (Nash, et al., 2018) argue for greater attention in primary care facilities to the process of diagnosis to improve the quality of care, based on their findings from Canada.

In our study setting in Uganda, improving the rates of early diagnosis and treatment is important given access to, and affordability of, dialysis treatment for later stage kidney disease. Based on our findings several other factors affect the ways in which people react to a diagnosis, particularly a diagnosis which may be symptomless and 'chronic'. Leventhal and colleagues (Leventhal, et al., 2016) in their 'Common-sense model of illness self-management' describe how a model of acute illness shapes the way in which people respond to being diagnosed with a chronic condition. An acute illness is generally characterised by symptoms which cause someone to seek care, from a health service provider or to self-treat. In contrast, many chronic conditions are asymptomatic but 'the acute model leads patients to expect symptoms and a short time-line' (p.939) (Leventhal, et al., 2016), which is an approach that does not fit with the long-term management of asymptomatic progression. A delay in seeking care is often attributed to the lack of symptoms for conditions such as hypertension and diabetes (Musinguzi et al., 2018; Nnko et al., 2015; Rutebemberwa, Katureebe, Gitta, Mwaka, \& Atuyambe, 2013) but also for people living with HIV, before they experience significant illness as a 
result of the infection (Kawuma, Seeley, Mupambireyi, Cowan, \& Bernays, 2018; Seeley et al., 2019). Many infectious diseases, common in the Ugandan setting (malaria for example), provide symptoms which lead the person affected to seek immediate treatment (Ladner, Davis, Audureau, \& Saba, 2017). As Leventhal and colleagues (Leventhal, et al., 2016) note 'patients will not take drugs unless they perceive a need to do so, particularly if asymptomatic' (p939), in addition they may not, as we show in our findings, acknowledge that they have been told they have a condition, if they have no symptoms: a self-assessment which may be supported in the view of the patient by the 'failure' of the health services to offer treatment. This 'common-sense' assessment of health needs to be understood if people are to be encouraged to be screened for kidney disease and, if found affected but asymptomatic, supported to engage with follow-up and the monitoring of their condition.

\section{Conclusion}

Kidney disease causes both morbidity and mortality in rural Uganda, but in our study most people had a limited understanding of the condition, including of the asymptomatic nature of early stage disease. Our findings point to the importance of understanding the context in which people receive information on conditions which are new to them, the comparisons they may make with the progression of other conditions, and the ways in which they may interpret the type of treatment offered for conditions which they are told are serious.

\section{References}


Asiki, G., Murphy, G., Nakiyingi-Miiro, J., Seeley, J., Nsubuga, R. N., Karabarinde, A., . . . Sandhu, M. S. (2013). The general population cohort in rural south-western Uganda: a platform for communicable and non-communicable disease studies. Int J Epidemiol, 42(1), pp. 129-141. doi:10.1093/ije/dys234 Retrieved from http://www.ncbi.nlm.nih.gov/pubmed/23364209

Bukabau, J. B., Sumaili, E. K., Cavalier, E., Pottel, H., Kifakiou, B., Nkodila, A., . . . Delanaye, P. (2018). Performance of glomerular filtration rate estimation equations in Congolese healthy adults: The inopportunity of the ethnic correction. PLoS One, 13(3), p e0193384. doi:10.1371/journal.pone.0193384 Retrieved from http://www.ncbi.nlm.nih.gov/pubmed/29499039

Bukenya, D., Wringe, A., Moshabela, M., Skovdal, M., Ssekubugu, R., Paparini, S., . . . Seeley, J. (2017). Where are we now? A multi country qualitative study on access to pre-ART care services, a precursor for ART initiation. Sexually Transmitted Infections, 93(Suppl 3), p e052970.

Chilcot, J. (2012). The importance of illness perception in end-stage renal disease: associations with psychosocial and clinical outcomes. Seminars in dialysis, 25(1), pp. 59-64. doi:10.1111/j.1525-139X.2011.00987.x Retrieved from https://www.ncbi.nlm.nih.gov/pubmed/21967476

Crinson, I., Gallagher, H., Thomas, N., \& de Lusignan, S. (2010). How ready is general practice to improve quality in chronic kidney disease? A diagnostic analysis. British Journal of General Practice, 60(575), pp. 403-409.

Daker-White, G., Rogers, A., Kennedy, A., Blakeman, T., Blickem, C., \& Chew-Graham, C. (2015). Non-disclosure of chronic kidney disease in primary care and the limits 
of instrumental rationality in chronic illness self-management. Social Science and Medicine, 131, pp. 31-39.

Delanaye, P., Mariat, C., Maillard, N., Krzesinski, J. M., \& Cavalier, E. (2011). Are the creatinine-based equations accurate to estimate glomerular filtration rate in African American populations? Clinical Journal of the American Society of Nephrology, 6(4), pp. 906-912. doi:10.2215/CJN.10931210 Retrieved from http://www.ncbi.nlm.nih.gov/pubmed/21441133

Ene-lordache, B., Perico, N., Bikbov, B., Carminati, S., Remuzzi, A., Perna, A., . . Remuzzi, G. (2016). Chronic kidney disease and cardiovascular risk in six regions of the world (ISN-KDDC): a cross-sectional study. The Lancet Global Health, 4(5), pp. e307-e319. doi:10.1016/S2214-109X(16)00071-1 Retrieved from https://www.ncbi.nlm.nih.gov/pubmed/27102194

Fabian, J., Kalyesubula, R., Tomlinson, L. A., Crampin, M., \& Naicker, S. (2019). SUN192 Epidemiology of Chronic Kidney Disease in East and Southern Sub-Saharan Africa-A multi-centre study from Uganda, Malawi and South Africa (the ARK Study). Kidney International Reports, 4(7), p S238.

Gaffney, H., Blakeman, T., Blickem, C., Kennedy, A., Reeves, D., Dawson, S., . . . Rogers, A. (2014). Predictors of patient self-report of chronic kidney disease: baseline analysis of a randomised controlled trial. BMC family practice, 15(1), $\mathrm{p}$ 196. doi:10.1186/s12875-014-0196-3 Retrieved from https://doi.org/10.1186/s12875-014-0196-3

Hart, L. A., \& Anderson, G. D. (2018). Methods of Estimating Kidney Function for Drug Dosing in Special Populations. Clinical pharmacokinetics, 57(8), pp. 943-976. 
doi:10.1007/s40262-018-0628-7 Retrieved from https://www.ncbi.nlm.nih.gov/pubmed/29357102

Jha, V., Garcia-Garcia, G., Iseki, K., Li, Z., Naicker, S., Plattner, B., . . Yang, C.-W. (2013). Chronic kidney disease: global dimension and perspectives. The Lancet, 382(9888), pp. 260-272. doi:10.1016/S0140-6736(13)60687-X Retrieved from https://www.ncbi.nlm.nih.gov/pubmed/23727169

Jutel, A. (2009). Sociology of diagnosis: a preliminary review. Sociology of Health and IIIness, 31(2), pp. 278-299.

Kalyesubula, R., Fabian, J., Nakanga, W., Newton, R., Ssebunnya, B., Prynn, J., . . . Tomlinson, L. A. (2020). How to estimate glomerular filtration rate in sub-Saharan Africa: design and methods of the African Research into Kidney Diseases (ARK) study. BMC Nephrology, 21(1), p 20. doi:10.1186/s12882-020-1688-0 Retrieved from https://doi.org/10.1186/s12882-020-1688-0

Kalyesubula, R., Hau, J. P., Asiki, G., Ssebunya, B., Kusemererwa, S., Seeley, J., . . . Newton, R. (2018). Impaired renal function in a rural Ugandan population cohort. Wellcome open research, 3

Kalyesubula, R., Nankabirwa, J. I., Ssinabulya, I., Siddharthan, T., Kayima, J., Nakibuuka, J., ... Hricik, D. (2017). Kidney disease in Uganda: a community based study. BMC Nephrology, 18(1), p 116. doi:10.1186/s12882-017-0521-x Retrieved from https://www.ncbi.nlm.nih.gov/pubmed/28372551

Kawuma, R., Seeley, J., Mupambireyi, Z., Cowan, F., \& Bernays, S. (2018). “Treatment is not yet necessary": delays in seeking access to HIV treatment in Uganda and Zimbabwe. African Journal of AIDS Research, 17(3), pp. 217-225. 
Kazley, A. S., Johnson, E. E., Simpson, K. N., Chavin, K. D., \& Baliga, P. (2014). Health care provider perception of chronic kidney disease: knowledge and behavior among African American patients. BMC Nephrology, 15, pp. 112-112. doi:10.1186/1471-2369-15-112 Retrieved from https://www.ncbi.nlm.nih.gov/pubmed/25012542

https://www.ncbi.nlm.nih.gov/pmc/articles/PMC4097045/

Kidney Disease Improving Global Outcomes (KDIGO) CKD Work Group. (2013). KDIGO 2012 Clinical Practice Guideline for the Evaluation and Management of Chronic Kidney Disease. Kidney International Supplement, 3, pp. 1-150.

Ladner, J., Davis, B., Audureau, E., \& Saba, J. (2017). Treatment-seeking patterns for malaria in pharmacies in five sub-Saharan African countries. Malaria journal, 16(1), pp. 353-353. doi:10.1186/s12936-017-1997-3 Retrieved from https://www.ncbi.nlm.nih.gov/pubmed/28851358

https://www.ncbi.nlm.nih.gov/pmc/articles/PMC5574241/

Leventhal, H., Phillips, L. A., \& Burns, E. (2016). The Common-Sense Model of SelfRegulation (CSM): a dynamic framework for understanding illness selfmanagement. Journal of Behavioral Medicine, 39(6), pp. 935-946. doi:10.1007/s10865-016-9782-2 Retrieved from https://doi.org/10.1007/s10865016-9782-2

Musinguzi, G., Anthierens, S., Nuwaha, F., Van Geertruyden, J.-P., Wanyenze, R. K., \& Bastiaens, H. (2018). Factors Influencing Compliance and Health Seeking Behaviour for Hypertension in Mukono and Buikwe in Uganda: A Qualitative Study. International journal of hypertension, 2018, pp. 8307591-8307591. 
doi:10.1155/2018/8307591 Retrieved from https://www.ncbi.nlm.nih.gov/pubmed/29854433

https://www.ncbi.nlm.nih.gov/pmc/articles/PMC5944291/

Naicker, S., Rahmanian, S., \& Kopp, J. B. (2015). HIV and chronic kidney disease. Clin Nephrol, 83(7 Suppl 1), pp. 32-38. doi:10.5414/cnp83s032 Retrieved from https://www.ncbi.nlm.nih.gov/pubmed/25725239

https://www.ncbi.nlm.nih.gov/pmc/articles/PMC4536633/

Nash, D. M., Garg, A. X., Brimble, K. S., \& Markle-Reid, M. (2018). Primary care provider perceptions of enablers and barriers to following guidelinerecommended laboratory tests to confirm chronic kidney disease: a qualitative descriptive study. BMC family practice, 19(1), pp. 192-192. doi:10.1186/s12875018-0879-2 Retrieved from https://www.ncbi.nlm.nih.gov/pubmed/30526501

https://www.ncbi.nlm.nih.gov/pmc/articles/PMC6287355/

Nguyen, T. V., \& Goldfarb, D. S. (2012). The older adult patient and kidney function. The Consultant Pharmacist, 27(6), pp. 431-444. doi:10.4140/TCP.n.2012.431 Retrieved from https://www.ncbi.nlm.nih.gov/pubmed/22698550

Nnko, S., Bukenya, D., Kavishe, B. B., Biraro, S., Peck, R., Kapiga, S., . . Seeley, J. (2015). Chronic Diseases in North-West Tanzania and Southern Uganda. Public Perceptions of Terminologies, Aetiologies, Symptoms and Preferred Management. PLoS One, 10(11), pp. e0142194-e0142194. doi:10.1371/journal.pone.0142194 Retrieved from https://www.ncbi.nlm.nih.gov/pubmed/26555896 
https://www.ncbi.nlm.nih.gov/pmc/articles/PMC4640879/

Perico, N., \& Remuzzi, G. (2014). Chronic kidney disease in sub-Saharan Africa: a public health priority. The Lancet Global Health, 2(3), pp. e124-e125.

Rosenberg, C. E. (2002). The tyranny of diagnosis: specific entities and individual experience. The Milbank Quarterly, 80(2), pp. 237-260.

Rutebemberwa, E., Katureebe, S. K., Gitta, S. N., Mwaka, A. D., \& Atuyambe, L. (2013). Perceptions of diabetes in rural areas of Eastern Uganda. Curationis, 36(1), pp. E1-E7. doi:10.4102/curationis.v36i1.121 Retrieved from https://www.ncbi.nlm.nih.gov/pubmed/23718775

Sagou Yayo, E., Aye, M., Konan, J. L., Emieme, A., Attoungbre, M. L., Gnionsahe, A., . .. Delanaye, P. (2016). [Inadequacy of the African-American ethnic factor to estimate glomerular filtration rate in an African general population: Results from Cote d'Ivoire]. Nephrol Ther, 12(6), pp. 454-459.

doi:10.1016/j.nephro.2016.03.006 Retrieved from https://www.ncbi.nlm.nih.gov/pubmed/27686033

Seeley, J., Bond, V., Yang, B., Floyd, S., MacLeod, D., Viljoen, L., . . the HPTN 071 study team. (2019). Understanding the Time Needed to Link to Care and Start ART in Seven HPTN 071 (PopART) Study Communities in Zambia and South Africa. [journal article]. AIDS and Behavior, 23 (4), pp. 929-946. doi:10.1007/s10461-018-2335-7 Retrieved from https://doi.org/10.1007/s10461$018-2335-7$ 
Slevin, J., \& Taylor, A. (2015). Understanding what the public know about their kidneys and what they do. Flndings from the Ipsos MORI survey July 2014. London: T. K. I. MORI.

Stanifer, J. W., Jing, B., Tolan, S., Helmke, N., Mukerjee, R., Naicker, S., \& Patel, U. (2014). The epidemiology of chronic kidney disease in sub-Saharan Africa: a systematic review and meta-analysis. Lancet Global Health, 2(3), pp. e174-181. doi:10.1016/S2214-109X(14)70002-6 Retrieved from http://www.ncbi.nlm.nih.gov/pubmed/25102850

Teasdale, E. J., Leydon, G., Fraser, S., Roderick, P., Taal, M. W., \& Tonkin-Crine, S. (2017). Patients' Experiences After CKD Diagnosis: A Meta-ethnographic Study and Systematic Review. American journal of kidney diseases, 70(5), pp. 656665. doi:10.1053/j.ajkd.2017.05.019 Retrieved from https://www.ncbi.nlm.nih.gov/pubmed/28764920

Walker, M. J., \& Rogers, W. A. (2017). Diagnosis, narrative identity, and asymptomatic disease. Theoretical medicine and bioethics, 38(4), pp. 307-321.

Willard, S., Holzemer, W. L., Wantland, D. J., Cuca, Y. P., Kirksey, K. M., Portillo, C. J., ... Nicholas, P. K. (2009). Does "asymptomatic" mean without symptoms for those living with HIV infection? AIDS care, 21(3), pp. 322-328.

Wright Nunes, J., Roney, M., Kerr, E., Ojo, A., \& Fagerlin, A. (2016). A diagnosis of chronic kidney disease: despite fears patients want to know early. Clin Nephrol, 86(2), pp. 78-86. doi:10.5414/CN108831 Retrieved from https://www.ncbi.nlm.nih.gov/pubmed/27345185

https://www.ncbi.nlm.nih.gov/pmc/articles/PMC5012189/ 
Wyatt, C. M., Schwartz, G. J., Owino Ong'or, W., Abuya, J., Abraham, A. G., Mboku, C., ... Wools-Kaloustian, K. (2013). Estimating kidney function in HIV-infected adults in Kenya: comparison to a direct measure of glomerular filtration rate by iohexol clearance. PLoS One, 8(8), p e69601. doi:10.1371/journal.pone.0069601 Retrieved from http://www.ncbi.nlm.nih.gov/pubmed/23950899 